\title{
Structural Non-Structural Protein-1 Virus Dengue of Risk Factors on Functional Interference Hepar
}

\author{
Susilowati Andajani \\ Department of Public Health Science and Preventive Medicine, Faculty of Medicine, \\ Universitas Airlangga, Surabaya (60131), Indonesia
}

\begin{abstract}
The causes of hepatic damage to DHF are mixed. Dengue virus can infect the liver and cause damage. Histopathology of the liver in cases of fatal dengue shows that hepatocytes and Kupffer cells can be the target of viral replication and there is involvement of apoptotic mechanism. This study aims to determine the association between dengue virus NS1 protein and degree of clinical manifestation of dengue infection with hepatic dysfunction. Blood samples after taking the serum, were examined for dengue virus NS1 protein and SGOT and SGPT examinations at the Surabaya Health Laboratory Center. Data analysis used Chi Square, Fisher's Exact, Anava and Dunnet $(\mathrm{a}=0.05)$. The results shows that the correlated variable significantly with dengue hemorrhagic manifestation degree was dengue virus NS protein $1(\mathrm{p}=0.047)$, with correlation strength of $26.8 \%$. Variables significantly correlated with liver dysfunction were degree of clinical manifestation of dengue fever $(\mathrm{p}=0.037)$ with correlation strength of $33.5 \%$ and dengue virus NS protein $1(\mathrm{p}=0.023)$ with correlation strength of $29.3 \%$. There was a significant relationship between the presence of dengue virus NS1 protein and the incidence of DHF. There was a significant relationship between the presence of dengue virus NS1 protein with hepatic dysfunction (SGOT and SGPT) in dengue virus infection.
\end{abstract}

Keywords: Non-structural protein 1, Hepatic function disorder, Dengue virus infection.

\section{Introduction}

Dengue fever (DD) and dengue hemorrhagic fever (DHF) is a major global problem. Two and a half to 3 billion people, especially those living in tropical and sub-tropical urban areas are at risk of dengue virus infection. $t$ is estimated that there are about 100 million cases of DD per year and as many as 500,000 dengue cases require hospitalization and the disease annually affects $90 \%$ of children under 15 . The average death rate in dengue reached $5 \%$ or the number of deaths per year about 25,000 people, while the death rate in some countries in Asia about $0.5-3.5 \%{ }^{1}$.

In Southeast Asia, Indonesia ranks first as a country with a high endemic predicate for DHF. In Indonesia and Surabaya the four serotypes of dengue virus are still endemic and in the period 2003-2005 DEN-2 (65\%) was the dominant serotype followed by DEN-3 (15\%), DEN-4 (12\%) and DEN-1 (8\%). The rate of dengue fever in Indonesia until July 2008 was about 78.18 per 100,000 population, while in Surabaya 76 out of 100,000 population with a mortality rate of $0.46 \%$ in 2008 . In 2007 Surabaya was included in 7 districts/cities with a high incidence of $\mathrm{DHF}^{2}$.

Hepar is one of the target organs of dengue virus infection. In patients with DHF or SSD, it was often found that in liver function dysfunction degrees mild to moderate and in some people occur hepatic encephalopathy that resulted in the death. Dengue virus can cause dengue virus hepatitis, where SGOT levels are higher than SGPT with a ratio of about 1: 1.5. In some cases, DHF can occur fulminant hepatitis, fulminant liver failure and acute liver failure ${ }^{3}$.

The incidence of hepatic dysfunction in patients with dengue hemorrhagic fever in some countries in Asia $30-90 \%$. A prospective study of patients with dengue infections in Thailand obtained $34.6 \%$ of 191 cases of hepatic dysfunction. Impaired hepatic function among patients without shock by $30 \%$ and patients with shock by $42.25 \%$. Approximately $8 \%$ of patients with hepatic 
dysfunction develop into hepatic encephalopathy. It is recommended the importance of detection of high levels of SGOT and SGPT to anticipate the possibility of disease development to hepatic encephalopathy ${ }^{4}$.

NS1 protein dengue virus is one of the nonstructural protein with a molecular weight of 46-50 kilodalton, a glycoprotein and the most immunogenic among the 7 types of non-structural protein dengue virus. Research in vivo shows that hepatocytes are the primary target cells of the dengue virus NS1 protein. Dengue virus infection causes apoptosis and endothelial or hepatocyte cell dysfunction. Until now the mechanism of pathogenesis of hepatic dysfunction disorder by NS1 protein dengue virus cannot be explained completely ${ }^{5}$. The purpose of this study was to determine that the presence of dengue virus NS1 protein is a risk factor for hepatic dysfunction (SGOT and SGPT) in dengue virus infection and calculate the risk of hepatic dysfunction due to the presence of dengue virus NS1 protein.

\section{Method}

The research design used in this research is analytic observational with the cross-sectional design. Selection of the design because at the beginning of the study on the members of the sample was not known whether or not there is a disruption of hepatic function and not known also the positivity of the examination of NS1 protein dengue virus. In addition, the prevalence of hepatic dysfunction in patients with dengue infection was quite high, in some countries in Asia about 30-90\%. Before conducting research the researcher first conducted a test of ethics at the Faculty of Medicine, Universitas Airlangga, Surabaya Indonesia ${ }^{6}$.

This study used 80 samples of patients with DD, DHF, SSD aged 12 years and above and hospitalization in the tropic room of men and women Dr. Soetomo GEeneral Hospital, Surabaya, Indonesia for 1 year and meet the inclusion criteria. Subject inclusion criteria include, 2-5 days of hot duration, No history of hepatitis, no history of abdominal typhoid pain and not alcohol drinkers. Samples who are willing to follow the research in advance fill out the informed consent sheets provided by the researchers.

DHF diagnostic criteria based on WHO criteria modification, with days of fever 2-5 days. Clinical criteria include, sudden high fever 2-5 days, for no apparent reason; presence of bleeding manifestations, including positive tourniquet test, petechiae, ecchymosis, gum bleeding, epistaxis, hematemesis and or melena; hepatic enlargement (hepatomegaly); signs of shock, rapid and weak pulse, narrowing of pulse pressure, hypotension, cold acral, damp skin and patient looking restless. Laboratory criteria include Thrombocytopenia $\left(<100,000 / \mathrm{mm}^{3}\right)$, Hemoconcentration, increase in hematocrit $20 \%$ or more. Diagnosis of dengue hemorrhagic fever is made when there are 2 or more clinical symptoms with thrombocytopenia and hemoconcentration. The sampling of a patient with simple random sampling ${ }^{7}$.

Method of data collection in this study are as follows, data on the patient's characteristic, complaints, symptoms, history of comorbidities, alcohol-related habits collected by interview using structured questionnaires, physical examination, complete blood, platelet count, hematocrit, bilirubin, widal test obtained from patient medical records, SGOT-SGPT levels, dengue virus NS1 protein obtained from the results of blood tests of patients with DD, DBD and SSD are taken as sample and hospitalization in Tropical Disease room male and female RSU. Dr. Soetomo Surabaya, Indonesia ${ }^{8}$.

The research material was the blood of DD, DBD and SSD from cubiti vein as much as $5 \mathrm{ml}$, then centrifuged and taken serum. Serum samples were then divided into 2 aliquots, for examination, serum SGOT levels and SGPT, dengue virus Protein NS1 with Platelia antigen NS1 dengue test. Physical examinations of hepatic physiological clinics (SGOT and SGPT) and detection of dengue virus NS1 proteins were performed in the clinical and immunological chemistry laboratory of Indonesian Center for Health Laboratory Surabaya, Indonesia ${ }^{9}$. Data of independent variable and dependent on nominal data scale were analyzed using Chi-square test with error rate $5 \%$. Statistical analysis was performed using SPSS version 23.0 (SPSS, Inc., Chicago, IL). The strength of the relationship was known by calculating the contingency coefficient for Chi-square test. Odd's Ratio to calculate the magnitude of risk ${ }^{10}$.

\section{Results}

Characteristics of the Subjects: The age of the patient varies between 12 to 54 years, mean age 23.20 \pm 8.10 years, at most 20 years. The age distribution of respondents does not follow the normal distribution curve. Age is then categorized into 3 groups, namely between the ages of 12 to 19 years, groups between ages 
20-29 years and groups between ages 30 to 54 years. Most (40\%) age group of patients $20-29$ years. The sex of the 80 respondents $(60 \%)$ is mostly male. Day fever based on the time of blood sampling, varied between day 2 and 5 days fever, mean duration of fever 3.9 days, at most 4 days (45\%). Day 2 fever (3.80\%), 3rd (28.80\%) and 5th (22.50). Most (40.00\%) sufferers of DD and patients with DBD degree II (54.55\%) aged 20-29 years. There is one DHF sufferer of age III 20 years old. In Table 1 the majority $(57.50 \%)$ of DD sufferers were women, whereas most dengue fever cases $(78.57 \%)$, dengue II (72.73\%) and dengue III (100\%) were male (table 1).

Based on statistical test results shows that there was a significant relationship $(p=0.022)$ between the presence of dengue virus NS1 protein with abnormal levels of SGPT in patients with DD, DBD. The strength of the resulting relationship is 0.272 . Mean dengue virus NS1 protein is a risk factor for the occurrence of SGPT disorders in dengue infection. Odd's Ratio calculation results for SGPT disturbed obtained value of 3.460 (CI $=1.292$ - 9.266; Table 2).

The result of the statistical test shows that there is a significant relationship $(p=0.023)$ between the presence of dengue virus NS1 protein with the occurrence of hepatic function disorder, with the strength of the relationship of 0.293 . Means NS1 protein dengue virus as a risk factor for the occurrence of DBD. Odd's Ratio calculation results for SGOT and SGPT were disturbed obtained value $4.603(\mathrm{CI}=1.127$ - 18800, Table 2$)$.

Table 1. Distribution of patients by sex and degree of clinical manifestation of dengue virus infection

\begin{tabular}{|l|c|c|c|c|}
\hline \multirow{2}{*}{ Sex } & \multicolumn{4}{|c|}{ Degree of Clinical Manifestations } \\
\cline { 2 - 5 } & DD & DHF degrees I & DHF degrees II & DHF degrees III \\
\hline Male & $17(42.50 \%)$ & $22(78.57 \%)$ & $8(72.73 \%)$ & $1(100.00 \%)$ \\
\hline Female & $23(57.50 \%)$ & $6(21.43 \%)$ & $3(27.27 \%)$ & $0(0.00 \%)$ \\
\hline
\end{tabular}

Table 2. The relationship between NSI protein dengue virus and hepatic dysfunction

\begin{tabular}{|c|c|c|c|c|}
\hline Protein NS1 dengue virus & Positive & Negative & $\mathbf{r}$ & $\mathbf{p}$ \\
\hline \multicolumn{5}{|l|}{ Levels of SGOT } \\
\hline Normal & $3(3.75 \%)$ & $11(13.75 \%)$ & 0.223 & 0.040 \\
\hline Abnormal & $34(42.50 \%)$ & $32(40.00 \%)$ & & \\
\hline \multicolumn{5}{|l|}{ SGPT Levels } \\
\hline Normal & $8(10.00 \%)$ & $21(26.25 \%)$ & 0.272 & 0.022 \\
\hline Abnormal & $29(36.25 \%)$ & $22(27.50 \%)$ & & \\
\hline \multicolumn{5}{|l|}{ Hepar Disruption } \\
\hline Normal & $3(3.75 \%)$ & $10(12.50 \%)$ & 0.293 & 0.023 \\
\hline SGOT/SGPT & $5(6.25 \%)$ & $12(15.00 \%)$ & & \\
\hline SGPT \& SGPT & $29(36.25 \%)$ & $21(26.25 \%)$ & & \\
\hline
\end{tabular}

\section{Discussion}

Checking levels of SGOT and SGPT is to see the picture of hepatic cell damage (hepatocytes). GOT enzymes are present in heart cells, liver, skeletal muscle, kidney, brain, pancreas, spleen and lung. In the hepatic GOT enzymes are present in the cytoplasm and mitochondrial hepatocytes. In cytoplasmic and hepatocyte mitochondrial deficiencies, GOT enzymes will emerge from cells so that levels of SGOT will increase. The high levels of this enzyme in the blood circulation were directly related to the amount of cell damage. Cell damage will be followed by an increase in SGOT levels within 12 hours and remain elevated for 5 days. Changes in SGOT levels in cell damage due to the acute inflammatory process are moderate, while in SGPT is highly sensitive ${ }^{11}$.

Such sensitivity occurs because the hepatocytes located closest to the central vein of each lobule normally have low oxygen tension and are highly susceptible to hypoxia. Sentrolobulus hepatocytes are 
injured when arterial hypotension causes reduced blood to enter the liver or when increased back pressure from right heart failure slows the blood out of the central vein; in this hypoxic damage, SGOT and SGPT levels rise to moderate levels ${ }^{12}$.

GPT enzymes are present in the liver, heart, muscle, kidney and hemost liver tissue. In dengue virus infection SGOT levels rise higher than SGPT levels. The mean rate of SGOT (80.88-84.73) $\mathrm{u} / \mathrm{l}$ is greater than the mean SGPT content (65.60-90.20) u/l. Dengue virus can cause dengue virus hepatitis, where SGOT levels are higher than SGPT with a ratio between SGOT and SGPT 1: $1.5^{13}$. In obstruction of acute extrahepatic bile ducts, SGPT levels rise higher than SGOT. SGOT: SGPT levels of more than 3: 1 were found in alcoholic liver disease. Increased levels of SGOT and SGPT up to 300 $\mu \mathrm{g} / \mathrm{l}$ levels are not specific for liver disorders. Increased levels of SGOT and SGPT> $1000 \mathrm{u} / \mathrm{l}$ may be present in viral hepatitis, liver ischemic disease (due to prolonged hypotension or acute heart failure) and liver damage due to toxins or drugs ${ }^{14}$.

The accumulation of intracellular dengue NS1 virus causes increased endocytic activity of hepatocytes and enhances the production of dengue virus after subsequent infection. This suggests that the dengue virus NS1 protein plays a role in the multiplication of dengue virus. Dengue virus replication induces synthesis of nitric oxide (NO) and RANTES and cell death by apoptosis ${ }^{13}$. Antibodies against the dengue virus NS1 protein cause inflammatory activation as well as endothelial cell apoptosis, whereas the severity of cytopathic effects and elevated levels of SGOT are associated with the rate of viral replication ${ }^{15}$.

Anti-NS1 dengue virus increases endothelial cell activation and leads to increased expression and secretion of IL- 6 and IL- 8 proteins and result in increased vascular permeability and systemic inflammation. Activation of endothelial cells by dengue virus NS1 protein will also increase the expression of ICAM-1 which causes adhesion of PBMC (peripheral blood mononuclear cell) in endothelial cells, resulting in damage to endothelial cells ${ }^{3}$.

The dengue virus NS1 protein was immunized in mice and obtained anti-NS1 antibody deposits in endothelial cells and resulted in endothelial cell apoptosis of portal venous and central liver venous veins. SGOT and SGPT levels increased after 2 days and NO involvement was found in endothelial cell apoptosis. In the histologic examination, hepatic tissue damage (hepatic fibrosis, hepatic fatty), mononucleosis phagocyte infiltration and cell apoptosis ${ }^{12}$.

\section{Conclusion}

The presence of dengue virus NS1 protein is a risk factor for SGOT disorders in dengue virus infections. The presence of dengue virus NS1 protein is a risk factor for SGPT disorders, where the risk of dengue sufferers with a positive NS1 protein for SGPT disorder is 3.46 times greater than those with dengue with a negative NS1 protein. The presence of the dengue virus NS1 protein is a risk factor for hepatic dysfunction in dengue virus infection, with the risk of dengue fever and dengue hemorrhagic dengue-positive NS1 dengue fever protein for hepatic dysfunction (SGOT and SGPT) of 4.60 times greater than with dengue fever sufferers and dengue hemorrhagic fever which is a negative NS1 protein.

Ethical Clearance: This research process involves participants in the survey using a questionnaire that was accordant with the ethical research principle based on the regulation of research ethic committee. The present study was carried out in accordance with the research principles. This study implemented the basic principle ethics of respect, beneficence, nonmaleficence and justice.

Conflict of Interest: The author reports no conflict of interest of this work.

Source of Funding: This study is done with individual funding.

\section{References}

1. Yudhastuti R, Rasjid A, Notobroto HB. Relationship of Environmental Condition, Container and Behavior with the Existence of Aedes aegypti Mosquito Larvae in an Endemic Area of Dengue Hemorrhagic Fever, Makassar. Pakistan J Nutr. 2016;15(3):295-8.

2. Sesulihatien WT, Kiyoki Y, Sasaki S, Safie A, Yotopranoto S, Sornlertlamvanich V, et al. Building the vector-control collaborative strategy in Dengue Fever: Case surabaya, Kuala Lumpur, Bangkok. Inf Model Knowl Bases XXVIII. 2017;292:94.

3. Tjahjono E, Maulana TD. Prediction of the number dengue hemorrhagic fever patients in district Jombang Regency using transfer function model 
approach. In: Journal of Physics: Conference Series. IOP Publishing; 2019. p. 12049.

4. Suparman R, Astelia C, Purwanti E, Widiyanti P. Application Design of Dengue Hemorrhagic Fever Patients Screening Using Naive Bayes Method. In: Journal of Biomimetics, Biomaterials and Biomedical Engineering. Trans Tech Publ; 2017. p. 20-8.

5. Yohan B, Wardhani P, Trimarsanto H, Sasmono RT. Production of recombinant dengue non-structural 1 (NS1) proteins from clinical virus isolates. Protein Expr Purif. 2017;129:53-9.

6. Kotaki T, Yamanaka A, Mulyatno KC, Churrotin S, Sucipto TH, Labiqah A, et al. Divergence of the dengue virus type 2 Cosmopolitan genotype associated with two predominant serotype shifts between 1 and 2 in Surabaya, Indonesia, 20082014. Infect Genet Evol. 2016;37:88-93.

7. Churrotin S, Kotaki T, Sucipto TH, Ahwanah NLF, Deka PT, Mulyatno KC, et al. Dengue virus type 1 strain isolated in Indonesia shows a close phylogenetic relationship with the strains that caused the autochthonous dengue outbreak in Japan in 2014. Jpn J Infect Dis. 2016;JJID-2015.

8. Wardhani P, Aryati A, Yohan B, Trimarsanto H, Setianingsih TY, Puspitasari D, et al. Clinical and virological characteristics of dengue in Surabaya, Indonesia. PLoS One. 2017;12(6):e0178443.

9. Widiyanti P. Digital Hematocrite Test, a New Breakthrough in the Medical Equipment for Non
Invasive Hematocrite Level Measurement in Dengue Patients. J Int Dent Med Res. 2017;10(3):1038-41.

10. Rasuna G, Sabila MP, Bramantoro T, Setijanto D, Zamzam A. Strawberry utilization empowerment program in low-temperature environment as a dental health promotion. J Int Oral Heal. 2019;11(7):26.

11. Wahyuni TS, Tumewu L, Permanasari AA, Apriani E, Adianti M, Rahman A, et al. Antiviral activities of Indonesian medicinal plants in the East Java region against hepatitis C virus. Virol J. 2013;10(1):259.

12. Morchang A, Lee RCH, Yenchitsomanus $\mathrm{P}$, Sreekanth GP, Noisakran S, Chu JJH, et al. RNAi screen reveals a role of SPHK2 in dengue virusmediated apoptosis in hepatic cell lines. PLoS One. 2017;12(11):e0188121.

13. Dionicio CL, Pena F, Constantino-Jonapa LA, Vazquez C, Yocupicio-Monroy M, Rosales R, et al. Dengue virus induced changes in $\mathrm{Ca} 2+$ homeostasis in human hepatic cells that favor the viral replicative cycle. Virus Res. 2018;245:17-28.

14. Ferreira RAX, de Oliveira SA, Gandini M, da Cunha Ferreira L, Correa G, Abiraude FM, et al. Circulating cytokines and chemokines associated with plasma leakage and hepatic dysfunction in Brazilian children with dengue fever. Acta Trop. 2015;149:138-47.

15. Lang J, Vera D, Cheng Y, Tang H. Modeling dengue virus-hepatic cell interactions using human pluripotent stem cell-derived hepatocyte-like cells. Stem cell reports. 2016;7(3):341-54. 